\title{
Acute Coronary Syndrome in a Patient With Single-Vessel Coronary Artery: Case Report
}

Bruno Dala Vedova Gomes Beato, ${ }^{\circledR}$ Carolina de Souza Galvão, ${ }^{\circledR}$ Eduardo Belisário Falchetto, ${ }^{\circledR}$ Eduardo Kei Marquesini Washizu, ${ }^{\bullet}$ Fábio Ávila Tofani, ${ }^{\odot}$ Juliano Moreira Reis Filho ${ }^{\bullet}$

Hospital Felício Rocho, Belo Horizonte, MG - Brazil.

\section{Introduction}

Anomalies of coronary arteries affect $1-2 \%$ of the population. ${ }^{1,2}$ They are associated with increased risk of sudden death and coronary artery injury during surgical procedures. ${ }^{1,2}$ Among the coronary artery anomalies, the single-vessel coronary artery disease subtype has a low incidence $-0.03-0.04 \%$ in patients without other heart diseases and $0.024 \%$ in patients with other heart diseases. ${ }^{2}$ Concomitant presence of acute coronary syndrome in these patients may have an impact on their prognosis and survival. ${ }^{3}$

Here we report a rare and challenging case of an 81-year-old woman with high-risk unstable angina undergoing emergency catheterization which indicated the presence of single-vessel coronary artery disease with lesions in multiple segments.

\section{Clinical case}

Eighty-one year-old female, with hypertension, diabetes, and non-dialysis chronic kidney disease, hospitalized due to a crushing retrosternal pain, initially occurring after physical exertion, that progressed to pain even at rest, and radiated to the shoulders and was accompanied by sweating. The electrocardiography showed sinus bradycardia, low voltage QRS in the frontal and horizontal planes, with end conduction delay in the right bundle branch, with no changes in the ST-segment and normal troponin. On physical examination the blood pressure was $220 \times 110 \mathrm{mmHg}$, with no other abnormal findings.

\section{Keywords}

Acute Coronary Syndrome; Coronary Vessels; Myocardial Ischemia; Atherosclerosis; Cardiac Catheterization; Stent.
The patient had unstable angina with a TIMI risk score of 4 and Grace score of 104, and the treatment protocol for acute coronary syndrome without ST elevation, with aspirin, ticagrelor and enoxaparin. The patient had recurrence of pain, and urgent coronary angiography was performed, which revealed left coronary artery bifurcation atherosclerosis with severe lumen occlusion $(80 \%)$ and calcification in the distal third. Type 3 anterior descending artery with severe lumen occlusion $(70 \%)$ in the middle third and moderate occlusion in the distal third (40\%). First diagonal branch with good diameter and atherosclerosis, with severe occlusion in the proximal-mid segment (80\%). Circumflex artery with good diameter and atherosclerosis, with severe occlusion in the middle third (90\%). Anomalous origin of the right coronary artery from the middle third of the anterior descending artery, with minimal wall irregularities (Figures 1 and 2). No evidence of cardiovascular abnormalities was found in the transthoracic echocardiography (left atrium $42 \mathrm{~mm}$, left ventricule ejection fraction $74 \%$.

The case was discussed by the Heart Team (interventional, surgery and clinical cardiologists). The patient had a Syntax Score I 21, Euroscore II $2.13 \%$ and STS score $5.16 \%$. According to the Syntax Score II, predicted four-year mortality was higher with percutaneous revascularization ( $25.9 \%$ vs. $16.4 \%)$. In addition, the interventional cardiology team found the percutaneous approach risky to perform, since it consists of implantation of multiple stents within one coronary artery.

Then, the surgical procedure consisted of arterial mammary grafting to the left anterior descending artery, and coronary artery bypass to first marginal branch, second marginal branch and diagonal branch. The surgery was successfully performed, without

Mailing Address: Carolina de Souza Galvão

Av. Contorno, 9530. Postal Code: 30110-934, Barro Preto, Belo Horizonte, MG - Brazil.

E-mail: carolinasouza195@gmail.com 


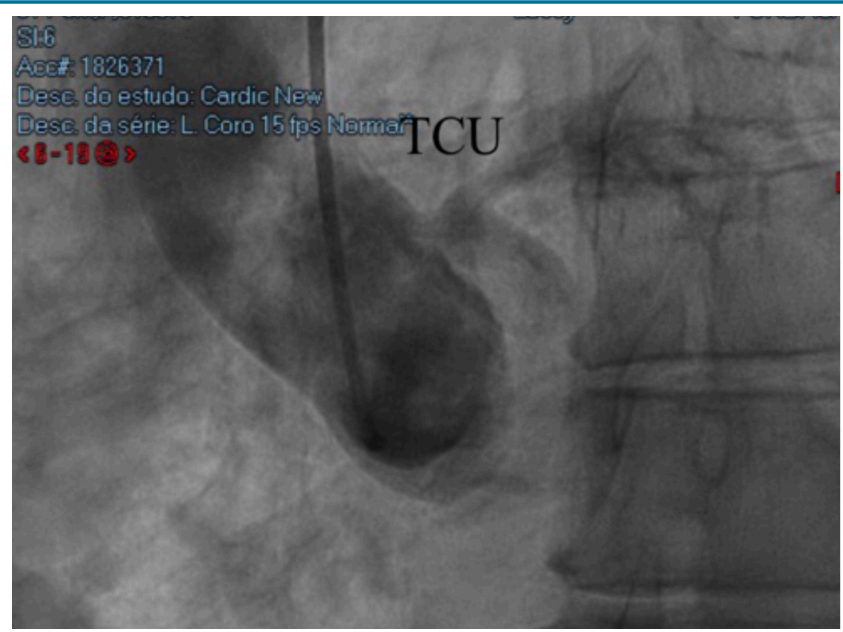

Figure 1 - Aortography showing single-vessel coronary artery arising from the left coronary sinus of Valsalva

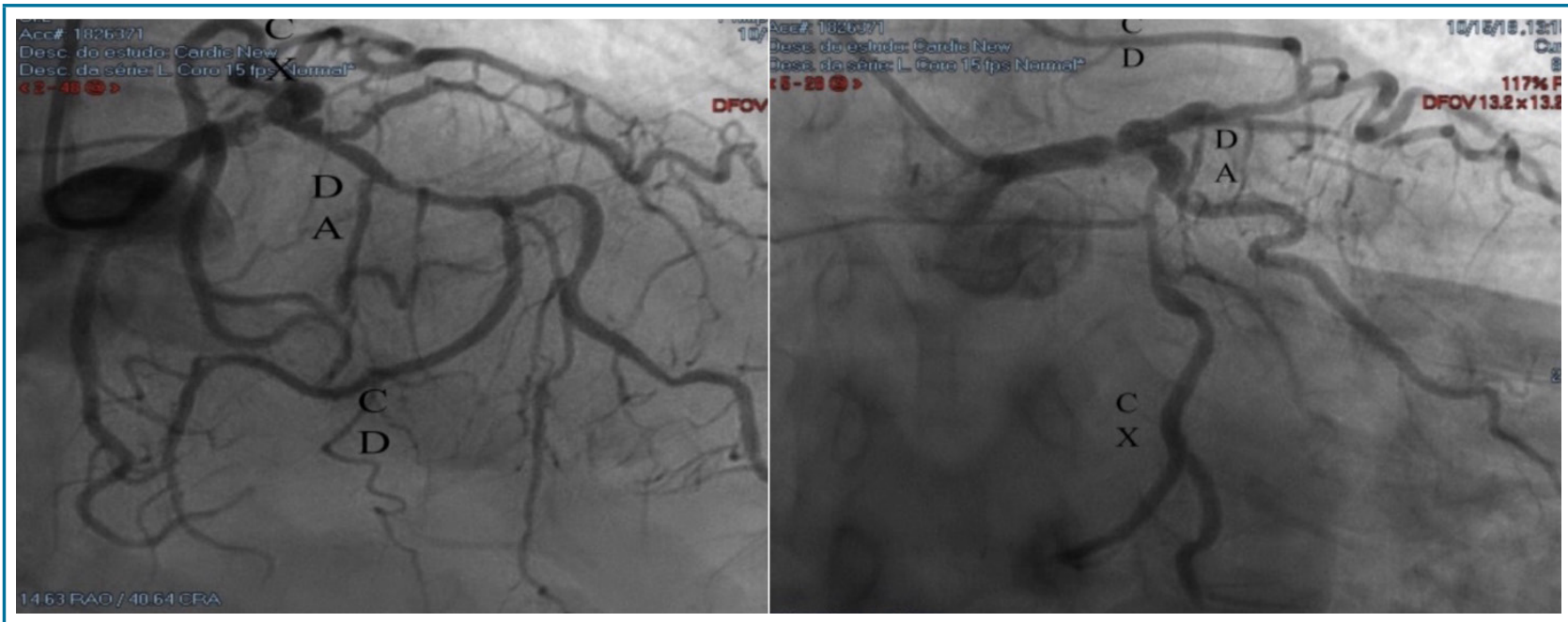

Figure 2 - Cranial-right anterior oblique view (B) and caudal-right anterior oblique view (C) showing severe obstruction in the proximal and middle third of the left coronary trunk, severe obstruction in the middle third of descending artery, anomalous origin of the right coronary artery from the middle third of descending artery and severe obstruction in the middle third of the circumflex artery

complications; the patient stayed at the intensive care unit for seven days, with good clinical course, until discharge. Pre-discharge transthoracic echocardiography showed preserved systolic function.

\section{Discussion}

Nearly $85 \%$ of patients with single-vessel coronary artery disease are asymptomatic, and the diagnosis of the disease is made by imaging tests during investigation of other cardiovascular diseases. Few cases (about 15\%) are symptomatic, with chest pain, syncope, and arrhythmia.
In these patients, ischemic symptoms may occur in the absence of obstructive coronary artery disease because of unfavorable anatomy or structure of anomalous vessels.

The present case illustrates a rare presentation of acute coronary syndrome caused by the anterior descending artery occlusion. Until 2005, only seven cases had been reported in the literature. ${ }^{2}$

Single-vessel coronary artery anomaly can be classified by the angiographic model developed by Lipton et al (1979) and adapted by Yamanaka et al. in 1990 (Figure 3). ${ }^{1}$ This classification is based on the location of the coronary artery ostium (right or left) and its direction, and its 


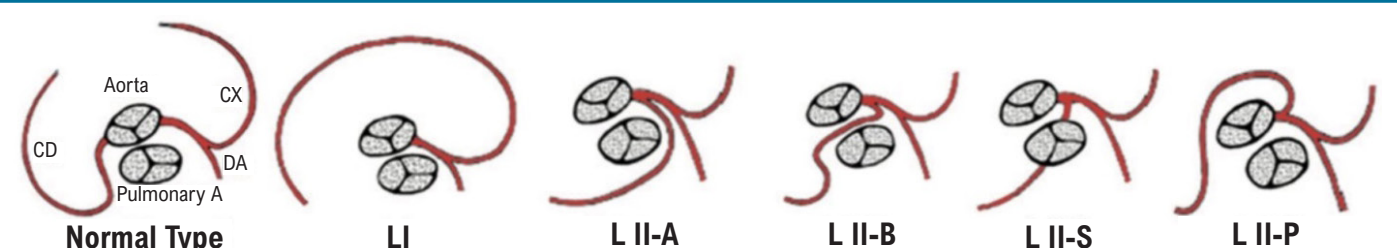

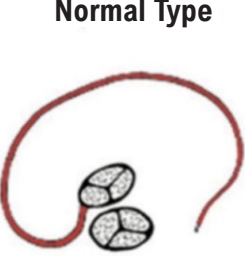

RI

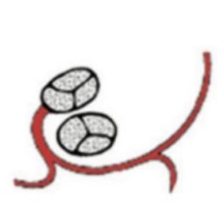

R II-A

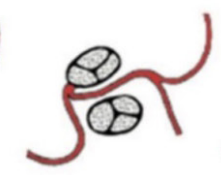

R II-B

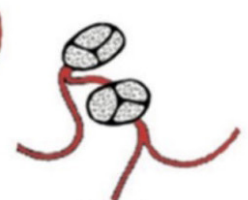

R II-S
L II-S

L II-P

Figure 3 - Angiographic classification of the single-artery coronary artery. Source: Guerios et al. ${ }^{1}$

relationship with other vessels. In single-vessel coronary artery type I, the single artery has a normal course, and collateral vessels compensate for the absent coronary artery. In type II, the anomalous coronary artery arises near the opposite coronary artery, passes through the heart base and its relation to large vessels may vary: anterior course in relation to pulmonary and aortic arteries (subtype A), between large vessels of the base (subtype B), posterior to the large vessels of the base (subtype $\mathrm{P}$ ) and combinations of these (C). In type III, the proximal segment of the right coronary artery originates the anterior descending artery and the circumflex branch, separately. ${ }^{1,4,5}$ The present case is classified as type II A, since the anomalous coronary artery arises from the contralateral coronary artery, and the anterior artery flows the large vessels of the base.

Single coronary artery anomaly seems to be associated with higher incidence of atherosclerotic disease as compared with normal coronary artery, according to studies by Sharbaught et al., ${ }^{6}$ Lipton et al., ${ }^{4}$ and Fernandes et al.. ${ }^{7}$ When intervention is indicated, surgical therapy is the approach of choice, with endovascular approach and stent implantation (after a careful analysis of anatomical conditions - courses of the vessels, tortuosity, acute angles, among others). Angioplasty is a challenging approach even for experienced interventional cardiologists. ${ }^{8,9}$ In the present case, the presence of single coronary artery and severe lesions in multiple segments made the endovascular approach difficult, and the patient underwent myocardial revascularization successfully.

\section{Conclusion}

It is important to recognize anatomical variations of the coronary arteries and their implications to the best clinical decisions and planning of technical strategies when intervention is indicated. In the case of our patient, the presence of acute ischemia and severe lesions of multiple vessels at angiography, including single ostium (absence of collateral circulation), the discussion by the Heart Team and the experience of the cardiovascular surgery team were decisive in the decision of the best intervention approach to this patient, who had an excellent clinical outcome.

\section{Author contributions}

Conception and design of the research: Beato BDVG, Galvão CSS, Reis Filho JM. Acquisition of data: Galvão CSS, Reis Filho JM. Writing of the manuscript: Beato BDVG, Galvão CSS, Falchetto EB, Marquesini EK, Toffani FA. Critical revision of the manuscript for intellectual content: Beato BDVG, Falchetto EB, Marquesini EK, Toffani FA.

\section{Potential Conflict of Interest}

No potential conflict of interest relevant to this article was reported.

\section{Sources of Funding}

There were no external funding sources for this study.

\section{Study Association}

This study is not associated with any thesis or dissertation work.

\section{Ethics approval and consent to participate}

This article does not contain any studies with human participants or animals performed by any of the authors. 


\section{References}

1. Guerios EE, Andrade PMP, Melnick G, Barbosa Neto D S. Artéria coronária única. Rev Bras Cardiol Invasiva [online]. 2010. 18(2):226-30.

2. Teixeira ICD, Brant AX, Ares A, Sarbi B, Moscoso I, Salman AA. et al . Artéria coronária única submetida a angioplastia com implante de Stent. Arq Bras Cardiol.2005;84(1):55-8.

3. Kamana VK, Ramachandran P, Krishnan AM, Chowdary RK, Malpe UP. Anomalous Single Coronary Artery Presenting with Acute Myocardial Infarction. J Clin Diagn Res. 2016;10(12):OD01-OD02.

4. Lipton MJ, Barry WH, Obrez I, Silverman JF, Wexler L. Isolated single coronary artery: Diagnosis, angiographic classification, and clinical significance. Radiology. 1979;130(1):39-47.

5. Yamanaka O, Hobbs RE. Coronary artery anomalies in 126,595 patients undergoing coronary angiography. Cathet Cardiovasc Diagn. 1990;21(1):28-40.
6. Sharbaugh MJAH, White RS. Single coronary artery: analysis of the anatomic variation, clinical importance, and report of five cases. JAMA. 1974;230(2):243-6.

7. Fernandes ED, Kadivar H, Hallman GL, Reul GJ, Ott DA, Cooley DA. Congenital malformations of the coronary arteries: the Texas Heart Institute Experience. Ann Thorac Surg.1992;54(4):732-40.

8. Rigatelli G1, Cardaioli P. Endovascular therapy for congenital coronary artery anomalies in adults. J Cardiovasc Med (Hagerstown). 2008 Feb;9(2):113-21.

9. Elbadawi A, Baig B, Elgendy IY, Alotaki E, Mohamed AH, Barssoum K, et al. Single Coronary Artery Anomaly: A Case Report and Review of Literature. Cardiol Ther. 2018;7(1):119-23. 